\title{
Perceptions and attitude towards violence against women by their spouses: A qualitative study in Northwest Ethiopia
}

\author{
Tegbar Yigzaw $^{1}$, Yemane Berhane ${ }^{2}$, Nigussie Deyessa ${ }^{3}$, Mirgissa Kaba ${ }^{3}$
}

\begin{abstract}
Introduction: To stop violence against women by their spouses we need to understand how the specific society perceives and views such violence. Then and only then can we institute effective and acceptable strategy to tackle the problem.

Objective: To assess community perceptions and attitude towards violence against women by their spouses

Methods: We conducted a qualitative study using focus group discussions and in-depth interviews with women, family arbitrators, healthcare workers, psychosocial experts, victims and perpetrator of violence, and law enforcement bodies in Gondar town, Northwest Ethiopia. Data were analyzed thematically using the Open Code Software.

Results: The normative expectation that conflicts are inevitable in marriage makes it difficult for society to reject violence. Acts of violence against women represent unacceptable behavior according to existing social and gender norms when there is no justification for the act and the act causes severe harm. There is considerable permissiveness of violent acts when the act is not regarded as wrong, there is socially acceptable premise, and the consequences are deemed mild. Marital rape is not understood well and there is less willingness to condemn it.

Conclusions: We conclude that there is insufficient understanding of violence against women in its contemporary use and many people hold a non-disapproving stance regarding violence against women by their spouses calling for a culturally sensitive information, education and communication intervention. [Ethiop. J. Health Dev. 2010(1):39-45]
\end{abstract}

\section{Introduction}

Spousal violence includes physical, sexual, or psychological aggression or coercion and is a pattern of behavior employed by one person in a relationship to control the other. The violence may include battering, burning, emotional blackmail, mockery or ridicule, threats of abandonment, confinement to the home, and the withholding of money and other family support (1).

Partner's violence occurs in all countries and transcends social, economic, religious, and cultural groups. Worldwide, one of the most common forms of violence against women is abuse by their husbands or other intimate male partners (2). Studies in Ethiopia have also shown that about one-half to two-third of women experience one or other forms of spousal abuse at least once in their lifetime (3-6).

Violence by spouse is an important public health concern associated with a host of health consequences for women victims (7-8). Even worse, the negative consequences extend beyond women's sexual and reproductive health to their overall health, welfare of their children, and even the economic and social fabric of nations (2).

As per many cultures, men have the right to control their wives' behavior and those women who challenge that right may be punished. In several countries studies found that violence is frequently viewed as the husband's right to "correct" an erring wife (2). The 2001 Demographic and Health Survey (DHS) of Ethiopia also reported that
$85 \%$ of women believe a husband is justified in beating his wife for at least one reason (9).

Some cross-sectional studies have been done in Ethiopia unveiling the pervasiveness of husband violence against women (3-6). The demographic and health survey also examined if respondents agreed to a list of violent acts (9). While previous studies brought to light the extent of the problem and acceptability of violent acts based on international discourse on violence against women, they did not bring to surface how men and women themselves define and make sense of spousal violence. However, if successful strategies aimed at violence against women are to be designed and mounted, perceptions and indigenous views need to be understood initially in adequate detail. In this study we assessed community perceptions and attitude towards husband violence against women by interviewing different stakeholders including victims and perpetrators of violence.

\section{Methods}

A qualitative study was conducted in Gondar town between December 2004 and February 2005. A total of six FGDs and five in-depth interviews were conducted with purposively selected subjects. FGDs were done with women, family arbitrators and professionals likely to have closer insight into violence against women and its contextual meaning. The family arbitrators included opinion leaders and religious figures representing the major religions in the country. Two groups from each kind were interviewed for scientific consideration (10). In-depth interviews were done with two victims of

\footnotetext{
Thpiego Ethiopia, P.O. Box 2881 code 1250, E-mail: tegbarys@yahoo.com, Addis Ababa, Ethiopia

${ }^{2}$ Addis Continental, Addis Ababa, Ethiopia

${ }^{3}$ School of Public Health, Addis Ababa University, Addis Ababa.
} 
violence, a perpetrator of violence, and law enforcement bodies (a judge, and a police officer) involved in resolving domestic matters. Flexible open-ended topic guides were used to facilitate FGDs and in-depth interviews. In-depth interview guides were informed by the preliminary results of the FGDs and tailored to the type of respondent. Issues the topic guides tried to address were how people define domestic violence, their experiences, the meanings they attach to acts of domestic violence, and their attitude towards them.

The principal investigator was responsible for doing the in-depth interviews and moderating the FGDs. Participatory techniques like free-listing, ranking and diagrams of violent acts were used to enrich the focus group discussions. Both FGDs and in-depth interviews were tape-recorded, and notes were taken during group discussions. The principal investigator also kept diary of the field experiences and reflections.

Data collection and analysis were undertaken simultaneously in line with the iterative nature of qualitative methods. Each session was followed by preliminary analysis that included verbatim transcription of tapes, translation of the material into English, and writing contact summaries. This guided planning for the next contact, and gave a chance to decide on continuing the data collection until a point of saturation (11). Analysis followed thematic approach. Coding was done using the Open Code software (12). Descriptive as well as interpretive codes were assigned to segments of the texts. Then similar codes were brought together forming categories. Categories were formed keeping the objective of the study in mind to be systematic while remaining open as much as possible. Major concepts were deciphered by repeated reading through the notes and memos, summarizing, and verifying. Matrix displaying helped to distill contradicting and parallel arguments forming attitudes towards acts of domestic violence.
As per the recommendations by the World Health Organization for research on domestic violence, measures were taken to maintain ethical standards (13). Informed consent was obtained from all study participants. Precautions were taken to ensure confidentiality and protect study participants. Ethical clearance was obtained from Faculty of Medicine/Addis Ababa University and permission was also secured from pertinent bodies in the study area. Feedback and discussion were also held with the community after completion of the study.

\section{Results}

Six focus group discussions and five in-depth interviews were carried out involving 46 participants. The focus group discussion participants were groups of professionals, women and family arbitrators. The professional group is composed of health professionals, teachers, sociologists and psychologists drawn from Gondar University, North Gondar Labor and Social Affairs Department and the North Gondar Women's Affairs Department. The women group participants were married or previously married. The family arbitrators ("yager shimaglie") group brought together men and one woman who understand the culture deeply and have several years of experience helping resolve husband-wife dispute. The group consisted of influential elderly people including religious figures representing Orthodox Christianity and Islam. With regard to in-depth interviewees, two of them were victims of violence and one was a perpetrator, while the rest were a judge and a police officer working on family affairs. There were roughly equal number of women and men in the study. The median age of study participants was 40 (range: 1990 years), one-half of them falling between 29 and 48 years. The socio-demographic characteristic of the study participants is summarized in Table 1.

Table 1: Socio-demographic Characteristics of Study Participants, Gondar, 2005 ( $n=46)$

\begin{tabular}{lll}
\hline Characteristics & Categories & Frequency (Percent) \\
\hline Sex & Male & $22(47.8)$ \\
& Female & $24(52.2)$ \\
& Single & $11(23.9)$ \\
Educational status & Married & $26(56.5)$ \\
& Divorced/Separated & $6(13.0)$ \\
& Widowed & $3(6.5)$ \\
& No formal education & $6(13.0)$ \\
& Primary education & $2(4.3)$ \\
& Secondary education & $14(30.4)$ \\
& Tertiary education & $20(43.5)$ \\
& Unknown & $4(8.7)$ \\
\hline & Government employee & $23(50)$ \\
& Housewife & $6(13)$ \\
& Retired & $6(13)$ \\
& Self employed & $4(8.7)$ \\
& Priest & $4(8.7)$ \\
\hline
\end{tabular}




\section{Perceptions and Experiences of Spousal Violence}

While individual participants had some difference in what counts as an act of spousal violence, the understanding was broad and subjective characterized by doing undesirable things on one's partner, against the interest of and/or without the consent of the person. Relatively more enlightened respondents provided a more formal definition of spousal violence encompassing physical, sexual, psychological and economic dimensions and different controlling behaviors. Beating and verbal aggression were mentioned by almost everyone as expressions of partner's violence.

Although the type and degree may vary from family to family, all participants believed spousal violence was rampant in the society. The following acts were mentioned as instances of intimate partner violence: beating with/without an object, use of weapons, burning, forced sex, unusual sex, insults, undermining, not listening to, calling names, intimidation, withholding money, extramarital affairs, annexing/selling/destroying properties of a partner, monitoring movements, preventing from learning/working, infecting one's spouse with HIV deliberately, forcing a woman to become pregnant or to have too many children, abandoning a woman, and denying equal rights on resources and decision-making. While acknowledging men as well as women could be violent, all believed men were the offenders in most cases, and women assaulted in reciprocity. As a result, most saw spousal violence as expression of male dominance.

Study participants disclosed real-life experiences of different forms of violence, which were communicated often as observations and less as self experience. Instances of physical violence included slaps, punches, kicking, beating with a stick, burning, and use of weapons. The first three were said to be rife in many families. In fact in the word of a woman who is FGD participant, "It is difficult to suppose an Ethiopian man won't raise his foot when he is angry with his wife." Potentially serious assaults were said to follow often suspicion of infidelity and jealousy. Stories of violent acts ranging from (intentional) severe burn injuries to murdering a partner by jealous husbands and wives were narrated.

In the in-depth interviews, survivors of violence said they were slapped, punched, kicked and beaten with an object. One of the victims said her husband had broken her teeth with a stone. A perpetrator of violence said at one time he had to take his wife to hospital due to the beating that caused her difficulty to eat.

Sexual violence was defined as forcing a woman to have sex against her will. In the women's group discussions and interview with an abuser, there were stories of coerced sex. Here again neither the FGD participants nor the in-depth interviewees (aside from the abuser) disclosed personal experience of forced sex. A woman recounted the story of a friend of hers who was bitter with her husband pressuring her to have too frequent sex which was causing her pain and "uterine problem". Another participant described the experience of her friend who developed a "uterine infection", calling for medical attention, and putting her on the verge of divorce due to the forced sex. The alleged abuser admitted that there were times he forced his wife into sex especially when he was drunk even by beating her up.

Examples of psychological abuse presented as experiences included insults, constant degradation, calling of names, and withholding family support. One survivor of violence stated that her husband used to say he should not have married a prostitute and that hurt her a lot. A young woman in the women's group also indicated that it always upsets her when her husband called her a dependent ("Tiwir"). Many women found withholding of money tormenting. Shouldering the domestic tasks, women suffer when men fail to provide money for the family and squander their property. The problem gets worse if the woman does not have her own income, which is often the case. Men also use the fact that they are the breadwinners to shut women up when they ask for money. But even when both the husband and wife are salaried, resources were said to be under the control of the husband. A comment by a survivor of violence is illustrative: "Most of all, I don't forget his withholding money when I asked; I mean you can't live unless you eat." In fact, according to a judge the presenting complaint for divorce was often economic issues much more than physical abuse. The other dimension of the problem was said to be men transferring/selling properties to a third party without the knowledge and/or consent of their spouses.

Yet another damaging experience for a married person was said to be having unfaithful partner. Involvement in extramarital affairs was believed to be more common among men. For a woman, risks of infection with HIV, diminution of the loving care, contraction of the financial support and subsequent disagreement leading to beating make the issue particularly unwelcome, according to study participants.

Many women considered abandonment by a husband as a severe violence especially once they have kids. They said men tend to get sick of their wives after some time in marriage, often after women give birth. Group of women said this was so partly due to fading of beauty due to excessive domestic responsibilities, motherhood and ageing. The fact that women are dependent on men was also mentioned as a reason for men losing interest in their wives. A survivor of violence located the change in behavior of her husband some time after she quit her job. Another scenario where a man would get tired of his wife was said to be his involvement with another woman. Desertion by a husband was said to be a very painful

Ethiop. J. Health Dev. 2010;24(1) 
experience for women because of their emotional attachment and economic dependence. Concern about children was also said to be a major factor. According to a survivor of abuse the worst thing that happened to her was abandonment by her husband. She would have liked to live with her husband enduring the violence for the sake of her daughter.

\section{Attitude towards Spousal Violence}

Almost all study participants felt conflicts are part of marriage. They said disagreements are expected since marriage is a union of two people with differing thoughts and backgrounds. Moreover, the interaction existing between two people and, hence, a husband and wife is filled with emotions and there are times when emotions could override between any two persons resulting in conflict. The following quotations illustrate this sentiment. "When you live under one ceiling, conflicts are expected even between brothers and sisters let alone a husband and wife." (Survivor of violence) "The irony of marriage in our country is that there will be signature by "Yeneger Abat" during marriage (laughing). This implies that conflicts are expected in marriage. It is not possible to say there won't be arguments and conflicts in a family. It will always be there." (58-year old married woman)

Almost all participants said all forms of spousal violence were generally inappropriate. They preferred for a husband and wife to live in peace, do everything in agreement and resolve differences patiently and carefully. However, this stand was not maintained upon probation and further discussion on tangible experiences. The attitude of study participants towards physical violence was mixed. For many respondents, wife beating was acceptable because conflicts were expected in marriage and a man could beat his wife when he is angry especially if he is young. They said condemning beating was denying reality. As long as it was mild and did not inflict injury it was said to be acceptable. Even the police would decide to prosecute the offence mainly based on the severity and would go for reconciliation for otherwise mild attacks.

For this group, although it is not right to beat someone, it is part of life and, hence, acceptable. Moreover, some considered beating as a sign of love. They said those men who love their wives would beat them, and women who recognize beating to be a symbol of love would even try to trigger it. In fact, men as well as women in the focus groups indicated that they knew some women who said their husbands beat them because they loved them.

They also mentioned situations when a woman deserves to be beaten. They said if a woman was unfaithful to her husband or could not be corrected by reprimand she should be beaten. Similarly the other ground for favoring wife beating was the notion that a husband is responsible for disciplining and putting an erring wife on the right track. And a man not wanting to punish his wife would be criticized as unmanly and docile ("Yewond Alcha"). Study participants uttered many proverbs that highlighted the appropriateness of physical violence. Just a look at the following quotes excerpted from the focus group discussions with men and women is enlightening. "If $a$ husband should not beat his wife, whom should he beat then?" "What kind of husband is one who does not beat his wife?" "He beats me because he likes me. Who else should he beat? If he hated me, he would not talk to me, let alone beat me." "A husband is like a corrector and administrator. He is expected to beat, punish, correct and put his wife on the right track."

On the contrary many others opposed physical violence. They indicated that no one has the right to beat anyone; and beating could result in injury and death, and might sour the relationship resulting in divorce. They emphasized that a loving husband would not beat his wife. Instead he would care for and do nice things to the woman he loves. They said a person cannot be corrected by beating; and dialogue and patience were better options to manage conflicts. Criticizing the idea that an erring wife should be beaten a woman in one FGD made the following remark. "If beating is indicated for an erring person, men will not be exempted." Still victims of violence maintained they should have tolerated their husbands' violent behavior.

The attitude of respondents towards forced sex was also varied. While the majority of men FGD participants had favorable attitude towards it, majority of the participants in women's groups disapproved marital rape. Many respondents felt once a man and a woman have entered into marital contract, which they said is a legitimate and voluntary institution, it would be difficult to talk about coerced sex. They said involved parties have the obligation to provide sex to their partners. They reinforced their point by saying sex is the major reason a man and a woman would get married and added that it is difficult for men not to have sex while sleeping in one bed. There was also an opinion that sexual pleasure is a shared feeling bad for neither of them and, therefore, acceptable.

It was also added that the involved parties are expected to care for each other's feeling and one should have sex to please his/her partner even if $\mathrm{s} /$ he does not want to. Besides, there was a view that marriage is about helping one another and satisfying a partner's sexual desire is an instance of help a wife can do easily. They also said a married woman should not refuse sex as that might prompt her partner to involve in extramarital affairs.

"If you call my asking for sex with my wife a rape, what would you call then the illegal forced sex occurring outside marriage?" (Family arbitrators group).

According to the religious leaders who participated in the family arbitrators group, both Christianity and Islam

Ethiop. J. Health Dev. 2010;24(1) 
instruct women to comply with their husbands and especially in the latter case it explicitly instructs women to provide sex whenever their husbands demand it. Christianity was also said to forbid withholding sex from one's spouse. A cultural perspective mentioned to condone forced sex was that women do not express their sexual desire openly, and men would have to take the initiative, leaving matters of sex to their discretion. Similarly, a judge interviewee said the Family Law rules out the existence of marital rape; he said marital partners have legal obligation to provide sex to each other. This group did not even like the mention of forced sex in marriage. They said the word is inappropriate to the context.

On the other hand, many others believed anything done against the interest of a woman is violence and, therefore, having forced sex with a woman is unacceptable. They indicated that anything that has a component of force is wrong. It was said that women refuse sex for some reasons and a man coercing his wife is one who does not care about her feelings. Coerced sex was perceived as another dimension of male dominance. They substantiated their argument making reference to the undesirable consequences of forced sex like unwanted pregnancy, HIV infection and psychological trauma. They also emphasized that forced sex is reaping pleasure from the pain of a woman. One woman said, "As women get older and see that there is sexual incompatibility, they will go to the extent of seeking out a young wife for their husband in order that they live in peace." A gynecologist noted relating to his experience, "Many women long for their husbands to get off them during sex." The majority of women saw coerced sex as inappropriate. However, even when they felt that it was inappropriate for a man to have sex with his wife against her will, they were hesitant to call it a rape. They thought rape was not the right word in marital context.

Women mentioned a relatively consistent list of reasons when a woman might refuse sex like being on menses, risk of pregnancy, fatigue from work, and sickness. They said if a man forced his wife into sex despite telling him her reasons, it would be unacceptable as a loving husband who should have understood his wife's problems. Nonetheless they rejected not wanting to have sexual intercourse alone as a good reason for refusal.

The views of study participants towards psychological abuse were also varied. Many said verbal abuse could be acceptable for the following reasons. They said two people living together cannot help speaking at each other; and words would not hurt a woman. They also said sometimes women themselves like to be insulted. There was also an opinion that people usually said things they saw on that person. If one tarnishes his spouse's reputation by falsely alleging she is unfaithful, he will be condemned. However, if she is known to be unfaithful then the insults are acceptable.
On the other hand, many others condemned verbal abuse in marriage. They said saying degrading and demoralizing things hurt a woman's psyche. An abuser indicated he deliberately said things that he knew would wound his wife's morale. It was also said that insults often extended to families; and exchange of words could culminate in physical violence and damage the love partners had for one another. They advised differences to be resolved by dialogue. A quotation by a victim of violence might help to illustrate the impact of words: "He always nagged me. It is not a life if a person always nags you, if he nags you even at the time of meal." Participants argued against emotional abuse caused by allowing male extramarital affairs and discouraging women from opposing that. They said telling a woman to bear unfaithfulness was depressing and degrading.

It was also said that some women would rather endure violent relationships than divorce their husbands. One reason was the stigmatization of a divorced woman and her consequent reduced chance of remarriage. The other reason was the economic dependence of women on their husbands. The third and most important reason was the concern for the welfare of children. Women preferred to raise their children with their husbands not only because of financial considerations but also because they felt it would be best for the child to be nurtured by both parents. The emotional attachment of women to their husbands was yet another deterrent.

\section{Discussion}

Trustworthiness of the results was ensured by careful selection of informants with assistance of recruiters, establishing good rapport with study participants, triangulation, verbatim transcription, and preliminary analysis (12). Spousal violence was broadly understood as a potentially hurting act perpetrated against the interest and/or consent of one's partner. Instances of physical, sexual, psychological and economic abuses as well as controlling behaviors were discussed by study participants. In line with common knowledge men were consistently reported to be the offenders in most domestic violence incidents (2). However, respondents appeared to have mixed and opposite feelings. Judgment of what constitutes as violence hinged on a number of factors. One important consideration is the perceived cause of the violence. If the violence is triggered by an action that is socially unacceptable like infidelity, it is deemed justified. Justifications to allow domestic violence have been shown to be prevalent across cultures from different parts of the world. Researches have shown societies do differentiate between just and unjust causes of violence (2). The demographic and health survey of Ethiopia also indicated that the majority of women believed a husband is justified in beating his wife at least for one reason (9). Likewise, a Ugandan study reported $70 \%$ of men and $90 \%$ of women believed beating was justifiable for one or more situations (14). BBC News online public attitude poll also found that $40 \%$ of

Ethiop. J. Health Dev. 2010;24(1) 
respondents did not agree with the statement, "Domestic violence is not acceptable under any circumstances," implying there are permissible situations for domestic violence. The same survey also reported that $30 \%$ and $27 \%$ of interviewees accepted domestic violence if one partner has been unfaithful and has nagged the other, respectively (15). However, the same action could be met with different reaction as a function of the existing gender norms. For example, infidelity by men is more likely to be tolerated in Ethiopian society.

Another barometer to accept or reject an act of violence is its perceived severity or the potential harm it may inflict. Many people are less willing to qualify slaps and kicks as acts of violence, while there is unanimous agreement about classification of use of weapons as an act of violence. Verbal aggressions are also taken lightly unless they are perceived as malicious and unwarranted. This is in agreement with research findings from different countries which showed that societies differentiate between thresholds of acceptable violence (2). Similarly, the BBC online survey demonstrated marked decline in acceptance of violence from $24 \%$ for one-off violence to $2 \%$ for violence needing medical attention (15).

There also seems to be a notion of condoning more prevalent violent acts as inevitable particularly when aroused by a recognizable triggering factor. There appears to be a fine line between conflict and violence, the latter sometimes used to resolve or silence disagreements. This also has an element of implying that the perpetrator is not responsible for the act under certain circumstances. Consequently, men and women alike will come to terms with the idea that the behavior is acceptable. This is consistent with the views of many researchers who view intimate partner violence as a socially learned behavior (16). Our results also found some mythical views that assert wife beating signifies love and women call for it. Although this was not substantiated by victims of violence in our study, a South African study had reported $34 \%$ of respondents personally agreed to the statement that beating signifies love (17).

Our study revealed the greatest ambivalence around marital rape. Most people seem to be of the opinion that once in marriage, rape is irrelevant. Although men were more likely to legitimize sex without consent in marital union, women were also reluctant to recognize it as rape or an act of violence for that matter. Unfortunately, cultural, religious and legal instruments in Ethiopia equate marriage with sexual entitlement nurturing the popular attitude $(18,19)$. This stands in stark contrast to the findings of BBC attitudinal survey, which revealed that more than three quarters of the interviewees (76\% of men and $79 \%$ of women) would end relationship in the incident of forced sex (15).
Another interesting variable in the equation is the fact that the perpetrator is a spouse. Community view is leveraged by this understanding so much so that people hesitate to count an act of violence as inappropriate despite a different stance when the parties are not in union. This is exemplified by the different sayings that legitimize and glorify husband beating and sexual coercion.

In our study there seems to be a distinction between what is disagreeable and what constitutes violence. People could say they prefer for it not to happen but fall short of perceiving it as an act of violence.

\section{Conclusion and Recommendation}

There is slight line between conflict and violence. The normative expectation of disagreements in marriage has overshadowed the likelihood to denounce resultant violence. While there are variations in views, people weigh the justness of the triggering cause and severity of the action against the context of local societal norms to judge an action as violence and unacceptable. Generally a non-disapproving attitude towards spousal violence against women prevails. However, there appears to be lack of full understanding of the meaning of violence against women in its contemporary use especially rape in marital context. We recommend the need to rectify unfavorable popular perceptions and views towards spousal relationship and violence against women through continuous culturally sensitive information, education and communication programs. The educational programs should seek to encourage a balanced relationship in marriage where the husband and wife live and treat each other as equal partners. They should help communities understand the negative consequences of violence against women. They should also help dispel myths, misconceptions and beliefs that nurture and condone violence against women. Finally it is also important for men and women to learn skills and attitude required to resolve differences and conflicts in a peaceful manner.

\section{Acknowledgements}

We would like to thank Action aid Ethiopia for funding the study, Gondar University for allowing the use of its premises during interview, and the study participants for sharing their thoughts.

\section{References}

1. Collymore Y, editor. Conveying concerns: women report on gender-based violence. Women's Edition Project, Population Reference Bureau. McArdle Printing Company; 2000: p. 5.

2. Heise L, Ellsberg M, Gottemoeller M. Ending violence against women.. Baltimore: Johns Hopkins School of Public Health, Population Information Program; 1999 December (Population Reports Series L, Number 11).

3. Deyessa N, Kassaye M, Demeke B, Taffa N. Magnitude, type and outcomes of physical violence

Ethiop. J. Health Dev. 2010;24(1) 
against married women in Butajira, Southern Ethiopia. Ethiop Med J 1998;36(2):83-92.

4. Gossaye Y, Deyessa N, Berhane Y, Ellsberg M, Emmelin M, Ashenafi M, et al. Women's health and life events study in rural Ethiopia. Ethiop J Health Dev 2003;17 Supp: 1-51.

5. Yigzaw T, Yibrie A, Kebede Y. Domestic violence around Gondar in Northwest Ethiopia. Ethiop J Health Dev 2004;18(3):133-139.

6. Kedir H. Magnitude and immediate outcomes of physical partner violence against women in Kofele District, Arsi Zone, Oromia Region [MPH thesis]. Addis Ababa: Addis Ababa University; 2004.

7. Heise L, Garcia-Moreno C. Violence by intimate partners. In: Krug EG, Dahlberg L, Mercy JA, Zwi $\mathrm{AB}$, and Lozano $\mathrm{R}$, editors. World report on violence and health. Geneva: World Health Organization; 2002. p. 87-121.

8. Campbell JC. Health consequences of intimate partner violence. The Lancet 2002;359:1331-36.

9. CSA, ORC Macro. Ethiopia demographic and health survey 2000. Addis Ababa, Ethiopia, and Calverton, Maryland, USA: Central Statistical Authority [Ethiopia] and ORC Macro [USA]; 2001. p. 31-33.

10. Hudelson P. Qualitative research for health programs. Geneva: World Health Organization; 1996, p. 15.

11. Miles M, Huberman A. An expanded sourcebook: qualitative data analysis. 2nd edition. London: Sage Publications; 1994. p. 50-54.
12. Dahlgren L, Emmelin M, Winkvist A. Qualitative methodology for international public health. Umea International School of Public Health. Umea, Sweden: Print Och Media. Umea University; 2004.

13. WHO. Putting women first: Ethical and safety recommendations for research on domestic violence against women. Geneva: World Health Organization; 2001.

14. Koenig MA, Lutalo $T$, Zhao F, Nalugoda F, Wabwire-Mangen F, Kiwanuka N, et al. Domestic violence in rural Uganda: evidence from a community-based study. Bulletin of the World Health Organization 2003;81(1):53-60.

15. BBC. Hitting home: domestic violence survey part II. In: online/ICM Bn, editor. London: BBC News; 2003. Available from: URL: http://news.bbc.co.uk/2/hi/uk_news/2753917.stm

16. Jewkes R. Intimate partner violence: causes and prevention. The Lancet 2002;359:1423-29.

17. Jewkes R, Levin J, Penn-Kekana L. Risk factors for domestic violence: findings from a South African cross-sectional study. Social Science \& Medicine 2002;55:1603-1617.

18. The Revised Family Code. Federal Negarit Gazetta of the Federal Democratic Republic of Ethiopia extraordinary issue No. 1/2000. The Revised Family Code Proclamation No. 213/2000. p.16-17

19. LHV $[C ̧>=3 / 4\} h h K^{\prime \prime}=" 3 / 4 \mathrm{u}$. $\} \mathrm{cw}$ QÓ KSÑ" ${ }^{2} \mathrm{~W} 3 / 4 \mathrm{~T}>[\AA$ >"Ç"É 'Øx< "ÓÉ T\}T>Á u.f $1995^{-}$.U. Ñê 14-22. 